\title{
ANÁLISE DA PERDA PRIMÁRIA DE IMPLANTES DENTÁRIOS INSTALADOS EM MAXILA RECONSTRUIDA COM ENXERTO AUTÓGENO DE CRISTA ILÍACA
}

\author{
Dreyson Motta Nicotari, Claudio Ferreira Nóia.
}

\section{Resumo}

A reabilitação através de Implantes Dentários possui como característica o restabelecimento da morfologia, função, estética e a saúde do sistema estomatognático. Atualmente, esse tipo de reabilitação é considerado o padrão ouro no tratamento para os pacientes edêntulos unitários, totais ou parciais. Com o advento de técnicas cirúrgicas modernas e assépticas, o uso de enxertos ósseos para reconstrução da região maxilo-facial tornou-se rotina. As reconstruções podem ser realizadas com a utilização de enxertos autógenos, alógenos, xenógenos ou aloplásticos. Em pacientes com necessidade de reconstruções com atrofia severa de maxila a crista ilíaca é considerada o padrão ouro, devido as propriedades de osteogênese, osteoindução e osteocondução. No entanto, falhas falhas podem ocorrer antes da reabilitação protética do implante, sendo chamada de falha primária, ou após a reabilitação protética do mesmo, sendo denominada de falha tardia. $O$ objetivo do presente trabalho é analisar a perda primária de Implantes Dentários instalados em maxilas reconstruídas com enxerto autógeno de crista ilíaca. Para isso, foram utilizados prontuários de pacientes submetidos à reabilitação com Implantes Dentários na Área de Cirurgia Buco-Maxilo-Facial da Faculdade de Odontologia de Piracicaba - FOP/UNICAMP, no período de Janeiro de 1996 a Dezembro de 2017. Desses prontuários foram coletadas e analisadas as seguintes variáveis: gênero, idade, região de instalação dos implantes, diâmetro e comprimento do implante instalado, tipo de perda do implante, região que o implante foi perdido, além do diâmetro e comprimento dos implantes perdidos.

\section{Palavras-chave:}

Enxerto ósseo, Implante Dentário, Perda primária

\section{Introdução}

Com o advento de técnicas cirúrgicas modernas e assépticas, o uso de enxertos ósseos para reconstrução da região maxilo-facial tornou-se rotina. As reconstruções podem ser realizadas com a utilização de enxertos autógenos, alógenos, xenógenos ou aloplásticos. Em pacientes com necessidade de reconstruções com atrofia severa de maxila a crista ilíaca é considerada o padrão ouro, devido as propriedades de osteogênese, osteoindução e osteocondução.

Este estudo justifica-se, pois a realização de estudos que visem analisar a perda tardia de implantes em áreas previamente enxertadas com osso autógeno de crista ilíaca é de extrema importância, necessidade e relevância, podendo assim permitir uma melhora nos índices de sucesso da Implantodontia á nível local (FOPUNICAMP), nacional e até mesmo mundial.

Sendo assim, o objetivo do presente trabalho é analisar a perda primária de Implantes Dentários instalados em maxilas reconstruídas com enxerto autógeno de crista ilíaca.

\section{Resultados e Discussão}

Foram avaliados um total de 1106 prontuários de pacientes submetidos a tratamento com implantes dentários. Desse total, 20 prontuários ( $1,8 \%$ da amostra) prontuários foram de pacientes submetidos à reconstrução de maxila com enxerto de crista ilíaca.

Desses 20 pacientes 11 (55\% eram do gênero feminino e 9 (45\% do gênero masculino, média de 58 anos de idade (variando de 36 até 72 anos).

Um total de 166 implantes foram instalados nesses 20 pacientes, sendo que $3(1,8 \%)$ foram perdidos. Uma dessas perdas $(0,6 \%)$ foi tardia e outras 2 precoces $(1,2 \%)$. A sobrevivência dos implantes foi de $98,2 \%$.
As perdas precoces ocorreram na região anterior da maxila, e o implante perdido foi de plataforma Cone Morse (CM), diâmetro regular $(3.75 \mathrm{~mm})$ e comprimento médio $(11 \mathrm{~mm})$, em individuo masculino, com idade de 50 anos, fumante.

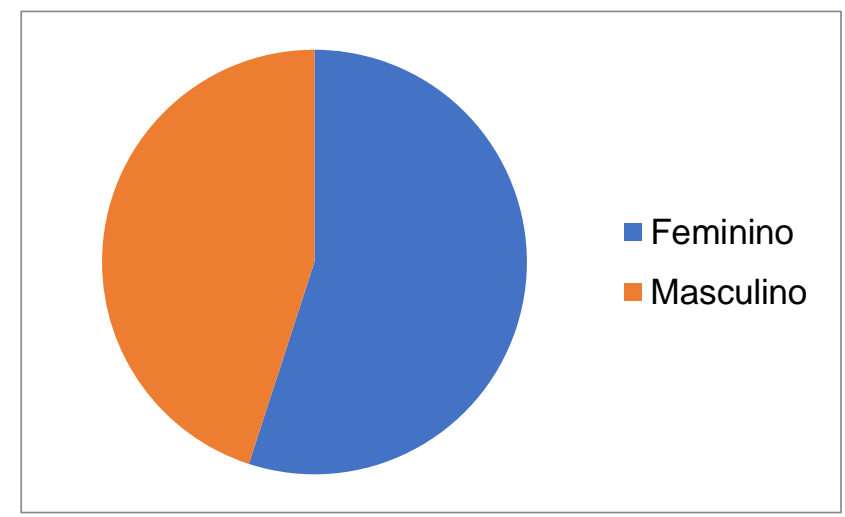

Gráfico 1. Distribuição da amostra em relação ao gênero.

\section{Conclusões}

A instalação de implantes dentários em maxilas reconstruídas com enxerto autógeno de crista ilíaca mostrou-se viável e previsível, com baixo índice de perda primária.

Ellis, E.R.; Tucker, M.R.; Hupp, J.R.; Cirurgia Oral e Maxilofacial Contemporânea - Rio de Janeiro: Elsevier. 2009; 5(4): 213-61

2 Mazzonetto R.; Duque Neto H.; Nascimento F.F.; Enxertos Ósseos em Implantodontia. Editora Napoleão. 2012; 1(1)

3 Tolstunov L. Implant zones of the jaws: implant location and related success rate. J Oral Implantol. 2007; 33(4): 211-20. 